
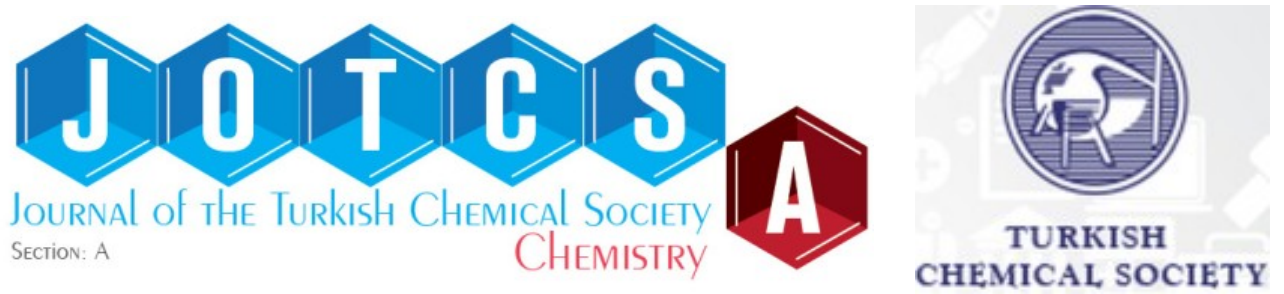

\title{
In silico, 6LU7 protein inhibition using dihydroxy-3-phenyl coumarin derivatives for SARS-CoV-2
}

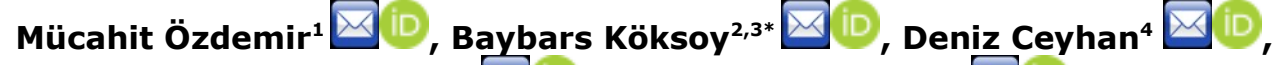 \\ Mustafa Bulut ${ }^{1} D$, and Bahattin Yalçın ${ }^{1 *}$ D \\ ${ }^{1}$ Marmara University, Department of Chemistry, 34722 Istanbul, Turkey \\ ${ }^{2}$ Gebze Technical University, Department of Chemistry, 41400 Kocaeli, Turkey \\ ${ }^{3}$ Bursa Technical University, Department of Chemistry, 16310 Bursa, Turkey \\ ${ }^{4}$ Tekirdağ Namık Kemal University, Department of Chemistry, 59030 Tekirdag, Turkey
}

\begin{abstract}
The new emerging coronavirus (SARS-CoV-2) has become a global health problem with very rapid transmission from person to person, causing severe acute respiratory problems. In the circumstance, the discovery of vaccines or drugs to eradicate or reduce the impact of the COVID19 has made it imperative to develop new approaches. In the current situation, many drugs on the drug bank have been researched computationally, and there has not been an emphasis on synthetic effort. We tested 42 coumarin derivatives (1a-14c) containing 14 different substituents, which are secondary metabolites of plants, and the anticoagulant Coumadin (warfarin) drug as a reference by Molecular Docking calculation technique on 6LU7 main protease of the coronavirus. Optimized geometries, electron motions and energy values of all coumarins were also determined using the Density Functional Theory (DFT) method. The drug properties of coumarins were estimated using the ADME-Tox test method. Coumarins formed strong interactions with HIS41, CYS145, and other amino acids in the active site of the main protease. In general, 6,7-dihydroxy3-phenylcoumarin derivatives gave relatively higher scores, and for all coumarins, biphenyl (for 10a, $-8.6 \mathrm{kcal} / \mathrm{mol} ; \mathbf{1 0 b},-8.3 \mathrm{kcal} / \mathrm{mol} ; \mathbf{1 0 c},-7.9 \mathrm{kcal} / \mathrm{mol}$ ) and 4-trifluoromethylphenyl (for 13a, $-8.1 \mathrm{kcal} / \mathrm{mol} ; \mathbf{1 3 b},-8.1 \mathrm{kcal} / \mathrm{mol} ; 13 \mathrm{c}-8.3 \mathrm{kcal} / \mathrm{mol}$ ) substituted coumarin had the highest score. The coumarins data reported in this study serves as a stepping stone for in vitro and in vivo experimental research for vaccine development purposes.
\end{abstract}

Keywords: COVID-19 main protease, SARS-CoV-2, Molecular docking, Drug design, Coumarins

Submitted: June 15, 2020. Accepted: July 09, 2020.

Cite this: Özdemir M, Köksoy B, Ceyhan D, Bulut M, Yalçın B. In silico, 6LU7 protein inhibition using dihydroxy-3-phenyl coumarin derivatives for SARS-CoV-2. JOTCSA. 2020;7(3):691-712.

DOI: https://doi.org/10.18596/jotcsa.753157.

*Corresponding authors. E-mail: byalcin@marmara.edu.tr, baybarsky@gmail.com.

\section{INTRODUCTION}

The novel emerging coronavirus (SARS-CoV-2; Severe Acute Respiratory Syndrome Corona Virus 2) is a virus that is the source of serious infections that cause lung and respiratory disorders in both humans and animals $(1,2)$. This acute respiratory disease, which first appeared in Wuhan, Hubei province of China in
December 2019, has spread worldwide in a short time, causing the COVID-19 (Corona Virus Disease 2019) pandemic (3, 4). The coronavirus, like other respiratory viruses, is transmitted by airborne virus droplets of people carrying the virus during breathing, coughing, sneezing, laughing, or speaking (5). Common symptoms seen in the COVID-19 are fever, 
cough, weakness, and shortness of breath ( 6 , $7)$. Also, a considerable number of people pull through the coronavirus asymptomatically and are potential carriers (8). After exposure to the virus, the time until the symptoms begin to appear is called the incubation period, on average 5-6 days, but it reported to go up to 14 or more days (9).

According to the analysis of the cases, the course of the disease or death among patients with diabetes, high blood pressure, heart disease or respiratory problems is quite high compared to other standard groups of patients (10-12). Among the complications associated with COVID-19, abnormal clotting of the blood has also been reported $(13,14)$. It is believed that anticoagulant drugs may play an essential role in preventing severe damage or death due to blood clots caused by a coronavirus (15). In general, there is no evidence that dicoumarol, warfarin (coumadin), acenocoumarol, ethyl biscoumacetate (tromexan), and phenprocoumon (marcoumar) type blood thinners (vitamin $\mathrm{K}$ antagonist) should be taken to prevent or remove blood clots caused by a coronavirus. Since blood thinners can cause bleeding, they should not be taken unless prescribed by a medical doctor. Coumarin can be considered as a useful target drug for coronavirus due to the natural presence of coumarins, secondary metabolites of plants, and high levels of pharmacophore properties such as antiviral, antimicrobial, anticoagulant and antibiotic (16-25).

In summary, our knowledge about COVID-19 and the effects of coronavirus on the body are increasing day by day. Researchers from around the world publish data almost every day, and some of the published research does not pass peer reviews. In all this information pollution, the findings of our study will contribute to drug development in the fight against COVID-19 by structure-activity analysis. In our study, the efficacy of 3-phenylcoumarin derivatives against the main protease (PBD: 6LU7) of the coronavirus was investigated using the Density Functional Theory and Molecular Docking calculation techniques.

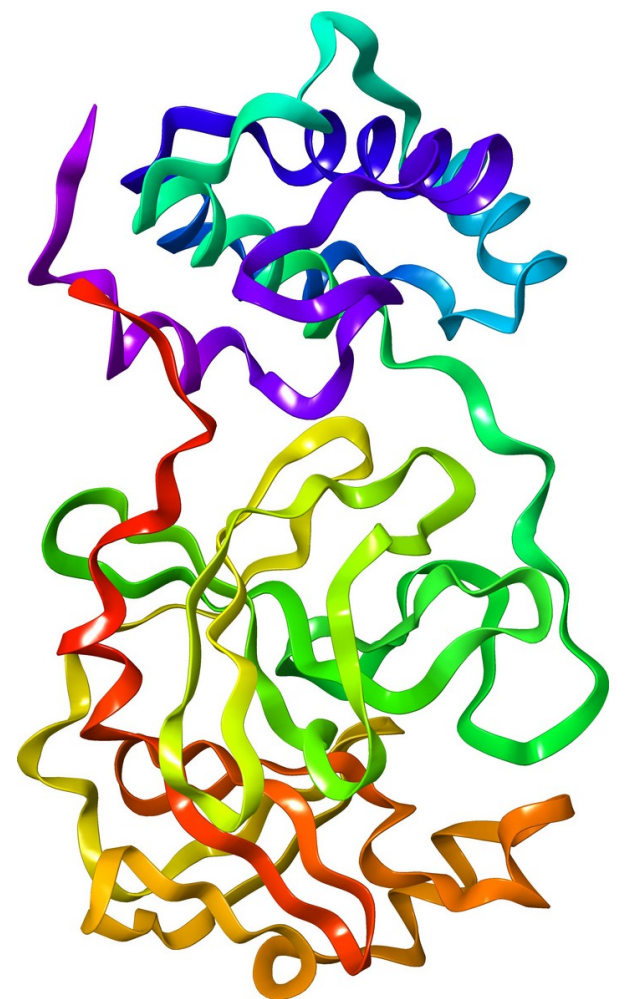

Figure 1. The structure of COVID-19 main protease (6LU7) with ribbon diagram.

\section{MATERIAL AND METHODS}

\section{Coumarins}

Natural organic 3-phenylcoumarin derivatives were selected for this study. 3-Phenylcoumarin derivatives are thought to have good scores, settlements to the active site of the receptor, and interactions with residues. $\mathbf{2} \mathbf{a}-\mathbf{c}, \mathbf{6 a}-\mathbf{8} \mathbf{b}$, 9a-c, 13a, 13b and 14a are synthesized compounds found in the literature. 1a-c, 3a-c, 10a-12c, 13c, 14b, and 14c are highly likely compounds to be synthesized. 


\section{DFT Studies}

Gaussian 09 (26) was preferred for theoretical calculations, and GaussView 6.0 (27) was used for visualization. Geometry optimizations of the complex were conducted with Becke-3-LeeYang-Parr's functional correlation (B3LYP) (2830 ) of the $6-311 \mathrm{G}(\mathrm{d}, \mathrm{p})$ basis set for the density functional theory (31) method. The geometry optimization of the complex was chosen as a stable form with $\mathrm{C} 1$ symmetry. In addition to geometry optimization, frequency analysis was also performed. The total electron density surface was calculated according to electrostatic potential values. The total electron surface was visualized using SCF/ESP as the density matrix.

\section{Molecular Docking Studies}

Autodock Vina (32) was used to estimate binding energy for coumarins and was repeatedly supported with AutoDock 4.2 (33). The X-ray crystal structure of COVID-19 main protease (PDB code: 6LU7) was resolved using an X-ray diffraction method with a resolution factor of $2.16 \AA$ was retrieved from the RCSB Protein Data Bank (https://www.rcsb.org). In the protein, the presence of water molecules from protein structure were removed and polar hydrogens and Kollman charges was added. Automatically the root of each ligand molecule is detected, and torsions were selected. All torsions of the ligand were allowed to rotate and checked for the selected residues. Blind docking was done to determine where the ligands would preferentially bind. The amino acids in the catalytic domain of 6LU7 $M^{\text {PRO }}$ were determined using Discovery Studio Visualizer 2020 (34). Pre-calculated grid maps were required for running the program, which was calculated using the AutoGrid program. The energy scoring grid box was set to $32 \times 32 \times 32$ dimension $(x, y$, and $z$ ) centered at $x=$ $10.712 ; Y=12.411 ;$ and $Z=68.831$ with 0.325 Angstroms grid points spacing assigned with default atomic solvation parameters. Lamarckian Genetic Algorithm was selected as a docking engine, with all the docking parameters set to default. After the Lamarckian Genetic Algorithm run, AutoDock reports the best docking solution along with $K_{\mathrm{i}}$ values for the docked complex, and the results are reported based on the cluster analysis. The coumarin derivatives with the lowest energy placement score were selected from 10 conformations obtained from vina calculations. The Schrödinger Maestro for academics program (35) was used for visualization processes, and Discovery Studio Visualizer 2020 was also partially utilized.

\section{ADMET Predictions}

In drug design, the estimation of the pharmacophore properties of the target molecules saves time and investment and brings them closer to the targeted molecule. It is used to estimate the parameters of absorption, distribution, metabolism, excretion, and toxicity (ADMET). SwissADME online database (36) was used to estimate ADME parameters of the coumarin derivatives. Toxtree-v3.1.0.1851 software was used to estimate the toxicity parameters according to Cramer rules with extensions.

\section{RESULTS AND DISCUSSION}

\section{DFT Studies}

Designed dihyrdoxycoumarin derivatives for 6 LU7 central protease inhibition were optimized with B3LYP-6-311G(d,p) basis set and HOMOLUMO presentation, electron density configuration, bandgap, and total energy value were given in Table S3-5. Generally, the total energy and band gap value for all designed coumarin derivatives have increased for electron-withdrawing substituents as compared to the electron-donating substituents (total energy; 551,000-2,170,000 kcal/mol, bandgap; 3.346-4.025 eV).

The electron distributions of all dihydroxy-3phenyl coumarin derivatives indicated that the m-electrons in the HOMO and LUMO are localized on the lactone ring and 3-phenyl part. Especially in electron-withdrawing substituents, this placement has been observed to shift towards the 3-phenyl group.

\section{Molecular Docking}

From a pharmacological perspective, 3phenylcoumarin derivatives tested as inhibitors of main coronavirus protease are compounds with significant anti-HIV, antidepressant, and antiviral properties. The binding energies obtained from the docking of the active site of the SARS-CoV-2 main protease 6LU7 and the various interactions between coumarins and the active site residues of the receptor are presented in Tables 1, 2 and 3. The types of interactions are expressed with colorized amino acids and they are explained in the legend. Primary protease amino acids HIS41, CYS44, MET49, SER144, CYS145, and GLU166, are thought to play essential roles in drug-receptor interactions (37). To compare the docking results, AutoDock Vina scores supported by AutoDock 4.2. scores. 
Table 1. Docking scores of 7,8-dihdyroxycoumarins on $6 \mathrm{LU7} \mathrm{M}^{\mathrm{PRO}}$.

\begin{tabular}{|c|c|c|c|c|}
\hline \multirow{2}{*}{ Ligands } & \multirow{2}{*}{ No } & \multirow{2}{*}{ Interactions } & \multicolumn{2}{|c|}{ Docking Score (kcal/mol) } \\
\hline & & & AutoDock & Vina \\
\hline & $1 \mathbf{a}$ & $\begin{array}{l}\text { ॰ARG188， oTHR190， oHIS41， oMET49, } \\
\text { ॰MET165， „CYS145 }\end{array}$ & -7.4 & -7.3 \\
\hline & $2 a$ & 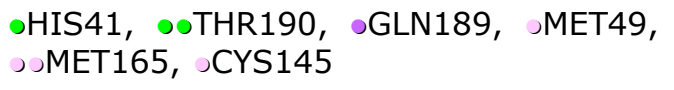 & -6.8 & -7.6 \\
\hline & $3 \mathbf{a}$ & 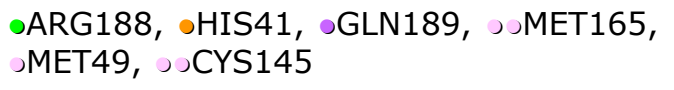 & -7.0 & -7.2 \\
\hline & $4 a$ & $\begin{array}{l}\text { oHIS41, ॰ASP187, oPHE140, ॰oHIS41, } \\
\text { oMET49, „CYS145 }\end{array}$ & -7.2 & -7.4 \\
\hline & $5 \mathbf{a}$ & $\begin{array}{l}\text { ॰ARG188, ॰THR190, oHIS41, oMET165, } \\
\text { oCYS145 }\end{array}$ & -7.3 & -7.3 \\
\hline & $6 \mathbf{a}$ & ॰०০HIS41, oLEU141, ০MET49, „CYS145 & -6.8 & -7.4 \\
\hline & $7 a$ & $\begin{array}{l}\text { oHIS41, oPHE140, JARG188, oMET49, } \\
\text { ॰ASP187, „CYS145, „MET49 }\end{array}$ & -7.1 & -7.8 \\
\hline & $8 \mathbf{a}$ & $\begin{array}{l}\text { oTHR190, ॰GLN189, oHIS41, oMET165, } \\
\text { oMET49, „CYS145 }\end{array}$ & -7.8 & -7.4 \\
\hline & $9 a$ & 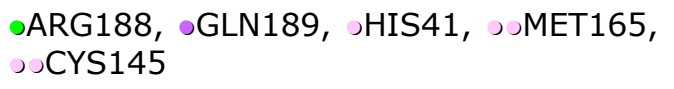 & -7.9 & -7.3 \\
\hline & $10 a$ & 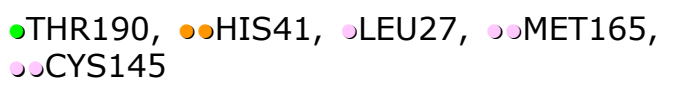 & -7.0 & -8.6 \\
\hline & $11 a$ & 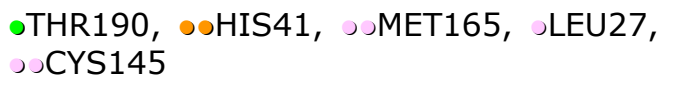 & -7.8 & -7.5 \\
\hline & $12 a$ & $\begin{array}{l}\circ G L U 166, \circ A R G 188, \circ L E U 141, \circ H I S 41, \\
\circ C Y S 145, \text { } \text { oMET165 }\end{array}$ & -6.9 & -7.6 \\
\hline & $13 a$ & 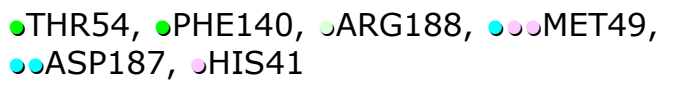 & -6.9 & -8.1 \\
\hline & $14 a$ & 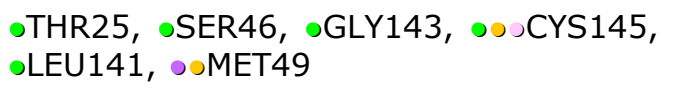 & -7.1 & -7.6 \\
\hline
\end{tabular}


Table 2. Docking scores of 6,7-dihdyroxycoumarins on $6 L U 7 M^{\text {PRO }}$.

\begin{tabular}{|c|c|c|c|c|}
\hline \multirow{2}{*}{ Ligands } & \multirow{2}{*}{ No } & \multirow{2}{*}{ Interactions } & \multicolumn{2}{|c|}{ Docking Score ( $\mathrm{kcal} / \mathrm{mol})$} \\
\hline & & & AutoDock & Vina \\
\hline & 1b & $\begin{array}{l}\text {-LEU141， JGLN189，JTHR190， JGLU166, } \\
\text { ॰CYS145 }\end{array}$ & -7.2 & -7.5 \\
\hline & 2b & $\begin{array}{l}\text { ॰SER144， oPHE140, „GLU166, oMET165, } \\
\text { ॰HIS163, ॰ CYS145 }\end{array}$ & -7.4 & -7.5 \\
\hline & 3b & $\begin{array}{l}\text { oHIS163, JGLU166, oMET165, oPRO168, } \\
\text { ॰.CYS145, }\end{array}$ & -7.5 & -7.4 \\
\hline & 4b & ๑০HIS41，॰ASN142， ০MET49， ০CYS145 & -7.0 & -7.7 \\
\hline & $\mathbf{5 b}$ & 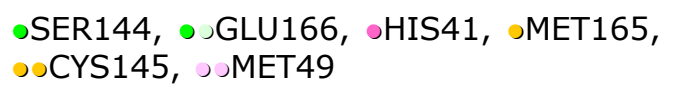 & -7.7 & -7.9 \\
\hline & 6b & 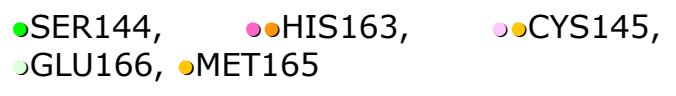 & -7.4 & -7.3 \\
\hline & 7b & 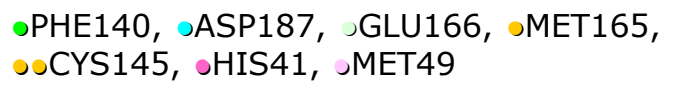 & -7.3 & -7.7 \\
\hline & $\mathbf{8 b}$ & 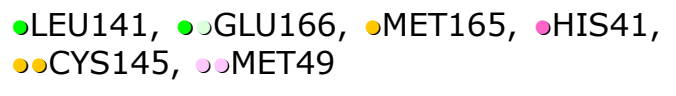 & -7.6 & -7.8 \\
\hline & 9b & 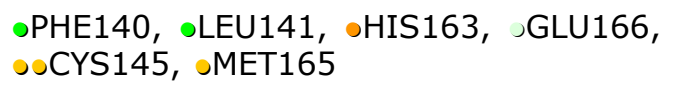 & -7.7 & -7.6 \\
\hline & 10b & $\begin{array}{l}\text {-LEU141, oHIS163， JGLU166, oMET165, } \\
\text { oCYS145, ○THR190, ○ OALA191 }\end{array}$ & -6.6 & -8.3 \\
\hline & 11b & 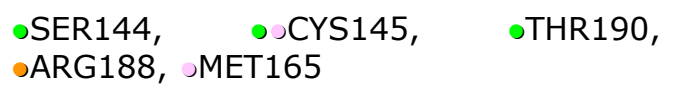 & -8.2 & -7.6 \\
\hline & 12b & 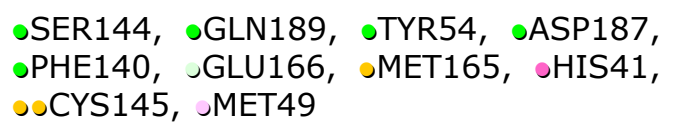 & -7.4 & -8.1 \\
\hline & 13b & 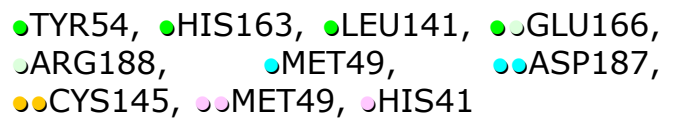 & -6.9 & -8.1 \\
\hline & 14b & $\begin{array}{l}\text {-GLY143, } \odot \text { 'SER144, } \\
\text {-THR190, oMET165 }\end{array}$ & -7.5 & -7.8 \\
\hline
\end{tabular}


Table 3. Docking scores of 5,7-dihdyroxycoumarins on $6 \mathrm{LU7} \mathrm{M}^{\mathrm{PRO}}$.

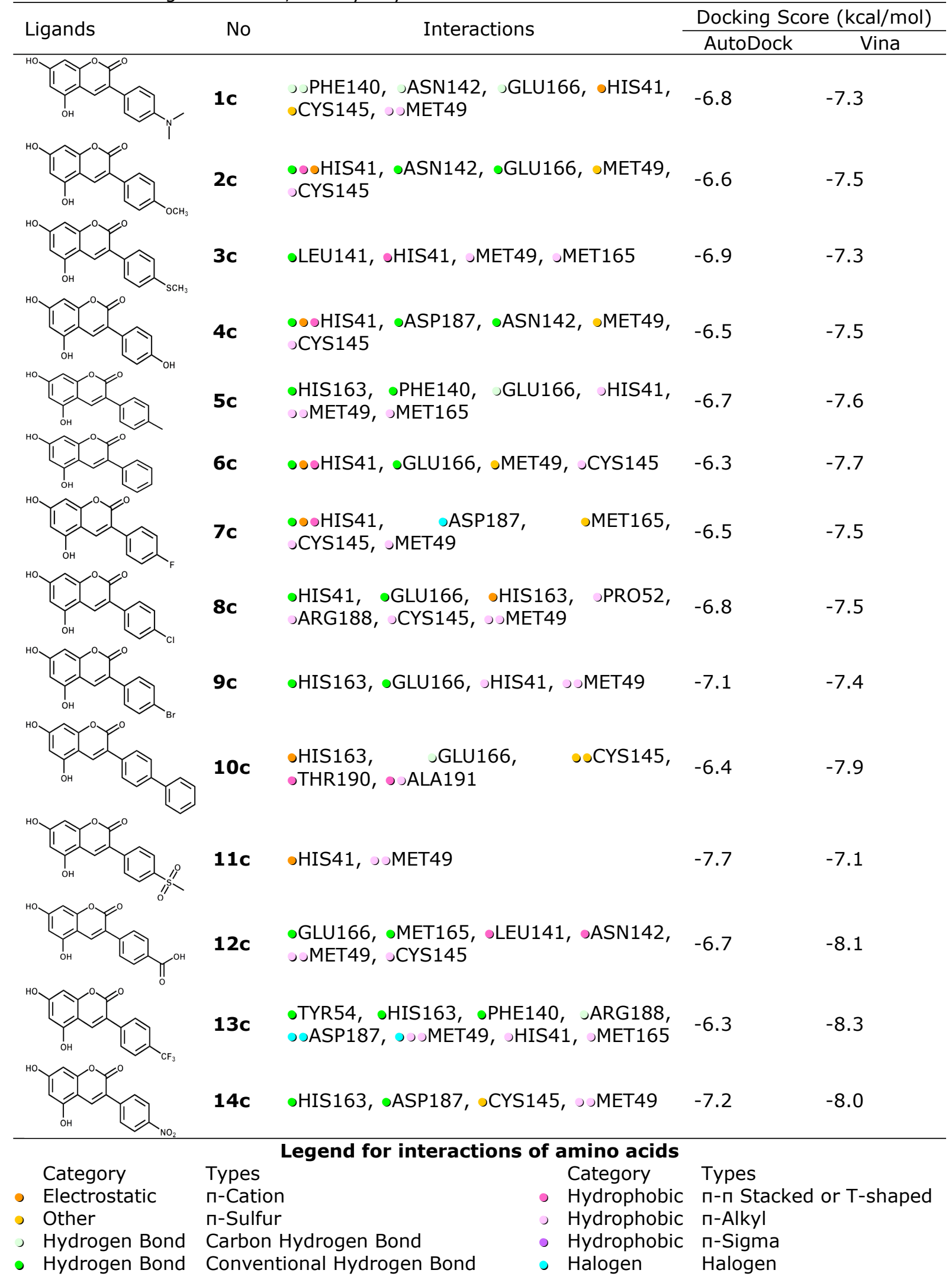


The first reference drug Coumadin (Warfarin) binding energies are $-6.9 \mathrm{kcal} / \mathrm{mol}$ for Vina and $-6.9 \mathrm{kcal} / \mathrm{mol}$ for AutoDock. Second reference drug Lopinavir binding energies are -7.5 $\mathrm{kcal} / \mathrm{mol}$ for Vina and $-6.9 \mathrm{kcal} / \mathrm{mol}$ for AutoDock. All 6,7-dihydroxy-3-phenylcoumarin, 7,8-dihydroxy-3-phenylcoumarin, and 5,7dihydroxy-3-phenylcoumarin derivatives (1a14c) have better binding energy than that of coumadin. The scores of all derivatives (1a14c) containing the same functional groups as structure-activity are consistent with each other. In the drug Coumadin, the lactone group formed the $\Pi$-alkyl bond with CYS145 and the ח-п T-shaped bond with HIS41. The oxygen of the ketone group formed a hydrogen bond with SER144. The hydrogen bond distance is 2.520 $\AA$, and the length of the hydrophobic bonds is in the range of 4.688 to $5.307 \AA$. In the drug Lopinavir, ligand-protein interactions are higher than all other compounds. The carbonyl oxygen of the amide group formed hydrogen bonds with ASN142 and GLU166. GLN189 formed a hydrogen bond with the opposite $\mathrm{H}-\mathrm{N}-$ of the amide group. GLU166 formed a hydrogen bond again with the C-4 of tetrahyropyrimidin-2-one group. HIS41 formed two $n$-cationic bonds with 1,6-diphenylhexane aromatic rings. Hydrogen bond lengths are 2.596/2.809 $\AA$ for ASN142, $1.921 / 3.486 \AA$ for GLU166, $2.516 \AA$ for GLN189. Electrostatic $n$-cation bond lengths are $4.471 \AA$ and $4.432 \AA$ for HIS41, respectively.

For 7,8-dihydroxy-3-phenyl coumarin derivatives, the compounds with the highest scores are $7 \mathbf{a}(-7.8 \mathrm{kcal} / \mathrm{mol}), 13 \mathbf{a}(-8.1$ $\mathrm{kcal} / \mathrm{mol})$ and 10a (-8.6 $\mathrm{kcal} / \mathrm{mol})$, respectively. In 7,8-dihydroxy-3-(4fluorophenyl) coumarin (7a), the hydroxy group at the C-7 position and lactone carbonyl group formed hydrogen bond with PHE140 and HIS41, respectively. The lactone group formed a $\Pi^{-}$ alkyl bond with CYS145. Hydrogen bond lengths are $2.673 \AA$ for HIS41 and $2.933 \AA$ for PHE140. The carbon hydrogen bond length is $3.116 \AA$ for ARG188. The length of hydrophobic bonds is between 4.384 and $5.068 \AA$.

In 7,8-dihydroxy-3-(4-trifluoromethylphenyl)coumarin (13a), the hydroxy group at the C-7 position and one of the fluorines of trifluorophenyl functional group formed a hydrogen bond with PHE140 and TYR54, respectively. And also, one of the fluorines of the trifluorophenyl functional group formed a nalkyl bond with HIS41. Hydrogen bond lengths are $2.725 \AA$ for TYR54 and 2.201 $\AA$ for PHE140. The length of hydrophobic bonds is between 4.045 and $5.038 \AA$. In 7,8-dihydroxy-3biphenyl-coumarin (10a), HIS41 formed a ${ }^{-}$ cation bond with each ring of the biphenyl functional group attached to the C-3 position. CYS145 also formed a n-alkyl bond with each ring of the biphenyl functional group attached to the $\mathrm{C}-3$ position. The hydrogen bond length is $2.573 \AA$. The length of hydrophobic bonds is between 4.286 and $5.470 \AA$. The compound with the lowest score of 7,8-dihydroxy-3phenyl-coumarin derivatives is $3 \mathbf{a}(-7.2$ $\mathrm{kcal} / \mathrm{mol})$. In 7,8-dihydroxy-3-(4methylthiophenyl)-coumarin (3a), the hydroxy group at the $\mathrm{C}-8$ formed a hydrogen bond with ARG188. CYS145 formed r-alkyl with the methylthiophenyl group at the $\mathrm{C}-3$ position and hydrophobic alkyl bond with the methylthio group. HIS41, on the other hand, formed an electrostatic $\pi$-cation bond with the methylthiophenyl group. The hydrogen bond length is $1.904 \AA$. The length of hydrophobic bonds is between 3.527 and $5.443 \AA$. In 7,8dihydroxy-3-phenylcoumarin derivatives, CYS145 formed a n-alkyl bond for all compounds (3a, 7a, 10a, and 13a).

For 6,7-dihydroxy-3-phenyl coumarin derivatives, the compounds with the highest scores are $\mathbf{1 2 b}(-8.1 \mathrm{kcal} / \mathrm{mol}), \mathbf{1 3 b}(-8.1 \mathrm{kcal} /$ $\mathrm{mol})$ and $\mathbf{1 0 b}(-8.3 \mathrm{kcal} / \mathrm{mol})$, respectively. In 6,7-dihydroxy-3-(4-carboxyphenyl)-coumarin

(12b), the hydroxy of the carboxyl group interacted with 3 different residues (ASP187, TYR54, and GLN189) by forming a hydrogen bond. The hydroxy group at the $\mathrm{C}-7$ position formed a hydrogen bond with PHE140, and the hydroxy group at the C-6 position formed a hydrogen bond with SER144. HIS41 formed a hydrophobic $\Pi-\Pi$ stacked bond with a 4carboxyphenyl functional group attached to the C-3 position. CYS145 also formed two n-sulfur bonds with coumarin main benzene and lactone ring (a-pyrone). The lactone group interacted with GLU166 by the $\pi$-donor hydrogen bond. The length of hydrogen bonds is between 2.242 and $2.987 \AA$, and the hydrophobic bond lengths are 4.662 and $5.012 \AA$. In 6,7-dihydroxy-3-(4trifluoromethylphenyl) coumarin (13b), GLU166 formed the conventional hydrogen bond with the hydroxy group at the $\mathrm{C}-7$ position and the $\pi$-donor hydrogen bond with the lactone ring. HIS163 and LEU141 formed the conventional hydrogen bond with the hydroxy group at the C-6 position. CYS145 also formed two n-sulfur bonds with coumarin main benzene ring and apyrone, again. As at 13a, one of the fluor of the trifluorophenyl functional group formed a hydrophobic n-alkyl bond with HIS41. The length of hydrogen bonds is between 2.056 and $3.006 \AA$, and the hydrophobic bond lengths are 3.994 and $4.846 \AA$. In 6,7-dihydroxy-3biphenyl-coumarin (10b), the hydroxy group at the C-6 position formed a conventional hydrogen bond with LEU141, and GLU166 
formed a n-donor hydrogen bond with GLU166. CYS145 formed two ח-sulfur bonds with coumarin main benzene and lactone ring. The hydrogen bond lengths are $2.172 \AA$ for LEU141 and $2.814 \AA$ for GLU166. The electrostatic bond length is $4.277 \AA$, and the hydrophobic bond lengths are $3.771 \AA$ for THR190:C,O;ALA191 and $5.435 \AA$ for ALA191. The compound with the lowest score of 6,7-dihydroxy-3-phenylcoumarin derivative is $\mathbf{6 b}(-7.3 \mathrm{kcal} / \mathrm{mol})$. In 6,7-dihydroxy-3-phenyl-coumarin (6b), the hydroxy group at the C-7 position formed a conventional hydrogen bond with SER144, and the lactone group interacted with GLU166 by a $\Pi$-donor hydrogen bond.

CYS145 formed two n-sulfur bonds with coumarin main benzene and lactone ring. The hydrogen bond lengths are $2.083 \AA$ for SER144 and $2.888 \AA$ for GLU166. The electrostatic bond length is $4.503 \AA$, and the hydrophobic bond lengths are $5.451 \AA$ for CYS 145 and $5.474 \AA$ for HIS163. In 6,7-dihydroxy-3-phenylcoumarin derivatives, CYS145 formed two n-sulfur bonds for all compounds' main benzene ring and lactone ring (6b, 10b, 12b, and 13b).

For 5,7-dihydroxy-3-phenyl coumarin derivatives, the compounds with the highest scores are 14c $(-8.0 \mathrm{kcal} / \mathrm{mol}), 12 \mathrm{c}(-8.1 \mathrm{kcal} /$ $\mathrm{mol})$ and $13 \mathrm{c}(-8.3 \mathrm{kcal} / \mathrm{mol})$, respectively. In 5,7-dihydroxy-3-(4-nitrophenyl)-coumarin (14c), HIS163 interacted with the uncoupled electron of the oxygen of the nitro group, forming a conventional hydrogen bond. The hydroxy group at the $\mathrm{C}-7$ position formed a conventional hydrogen bond with ASP187. CYS145 formed one $\Pi$-sulfur bond with a 4- nitrobenzene ring at the $\mathrm{C}-3$ position. The hydrogen bond lengths are $2.456 \AA$ for HIS163 and $2.951 \AA$ for ASP187, and the hydrophobic bond lengths are $4.238 \AA$ for MET49 and 5.164 $\AA$ for MET49, again. In 5,7-dihydroxy-3-(4carboxyphenyl)-coumarin (12c), the hydroxy group at the C-5 position formed a conventional hydrogen bond with MET165. The hydroxy of the carboxyl group interacted with GLU166 by forming a conventional hydrogen bond. CYS145 formed a $n$-alkyl bond with a lactone ring. The hydrogen bond lengths are 2.200 $\AA$ for GLU166 and $2.743 \AA$ for MET165, and the length of hydrophobic bonds is between 4.442 and 5.472 $\AA$. In 5,7-dihydroxy-3-(4-trifluoromethylphenyl) coumarin (13c), the hydroxy group at the $\mathrm{C}-7$ position and again the hydroxy group at the C-5 position and one of the fluor of trifluorophenyl functional group interacted with PHE140, HIS163, and TYR54 by conventional hydrogen bond, respectively. ARG188 formed a carbonhydrogen bond $(\mathrm{C}-\mathrm{H})$ with another of the fluor of the trifluorophenyl functional group. The $-\mathrm{CF}_{3}$ group interacted with HIS41 by a hydrophobic n-alkyl bond. The hydrogen bond lengths are $1.791 \AA$ for PHE140, 2.340 $\AA$ for HIS163, 2.697 $\AA$ for TYR54, and $3.227 \AA$ for ARG188. The length of hydrophobic bonds is between 4.111 and $5.498 \AA$. The compound with the lowest score of 5,7-dihydroxy-3-(4methylsulfonylphenyl)-coumarin derivative is 11c (-7.1 $\mathrm{kcal} / \mathrm{mol})$. In 5,7-dihydroxy-3-(4methylsulfonylphenyl)-coumarin, HIS41 formed electrostatic $\Pi$-cation bond with lactone ring. The electrostatic bond length is $4.275 \AA$ for HIS41, and the length of hydrophobic bonds is between 4.147 and $4.803 \AA$. 
A)

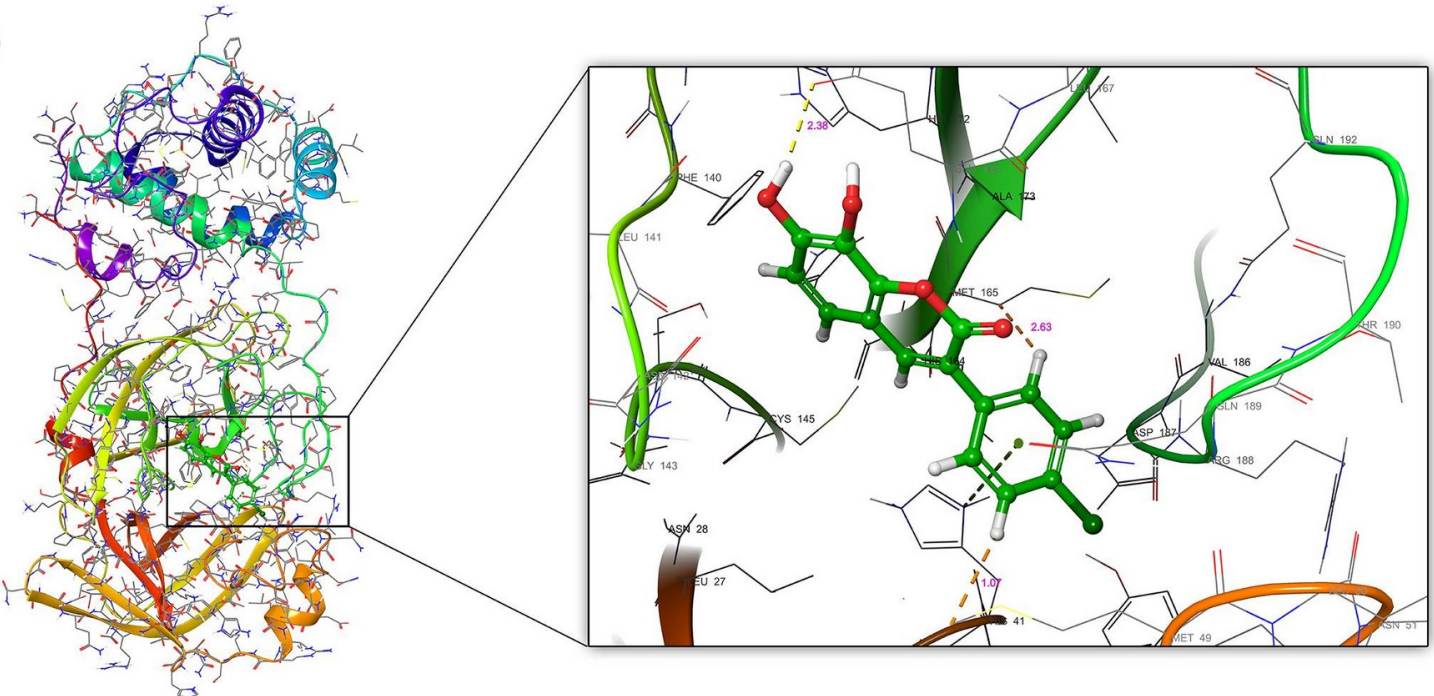

B)

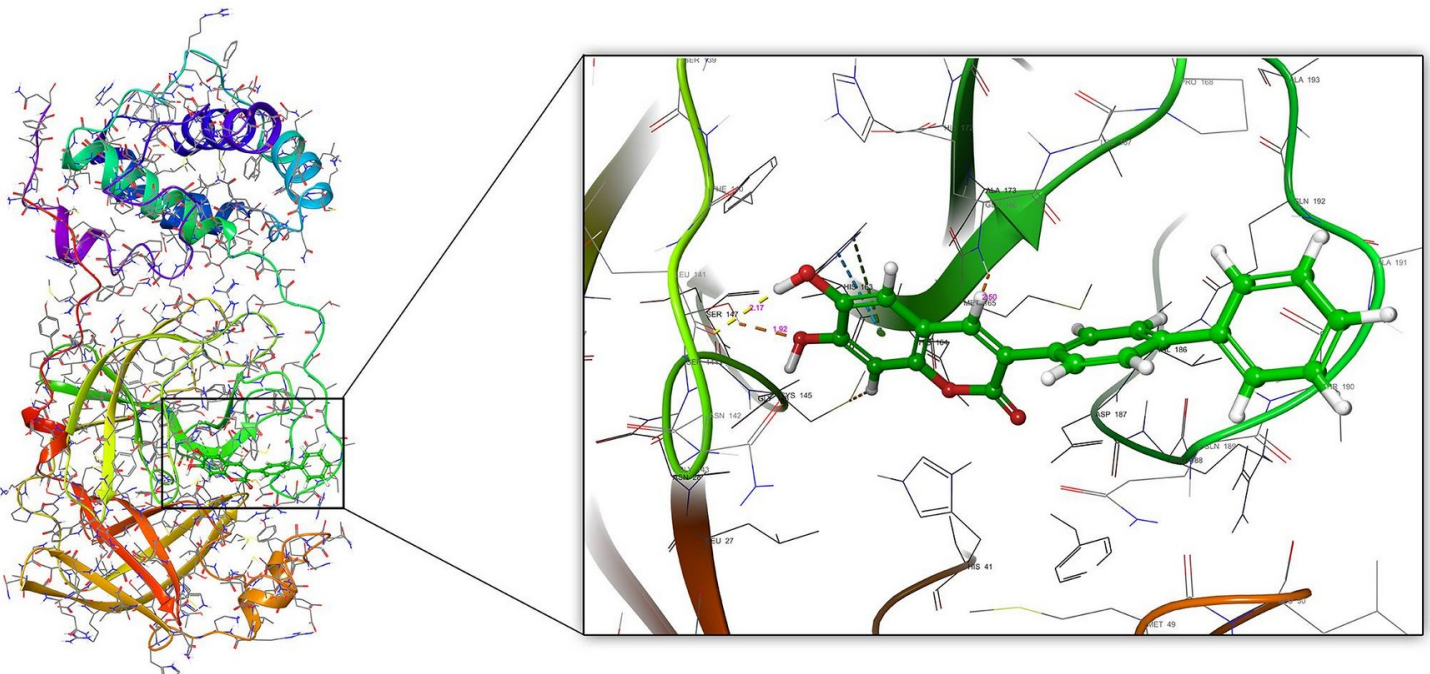

C)

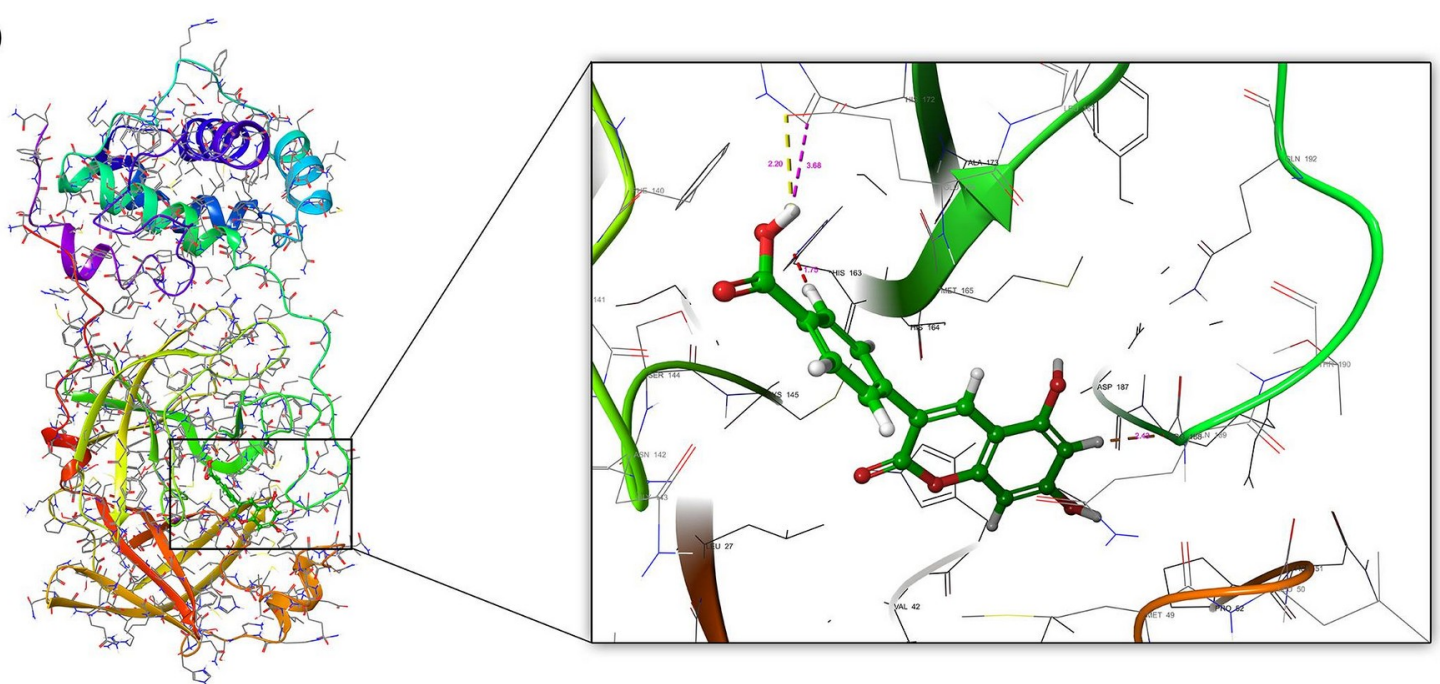

Figure 2. The interaction diagrams of 6LU7 main protease with coumarins in the catalytic domain (left, general, and right, focused on the active site). A for compound $\mathbf{8 a}$, B for compound $\mathbf{1 0 b}$, and $C$ for compound 12c. 

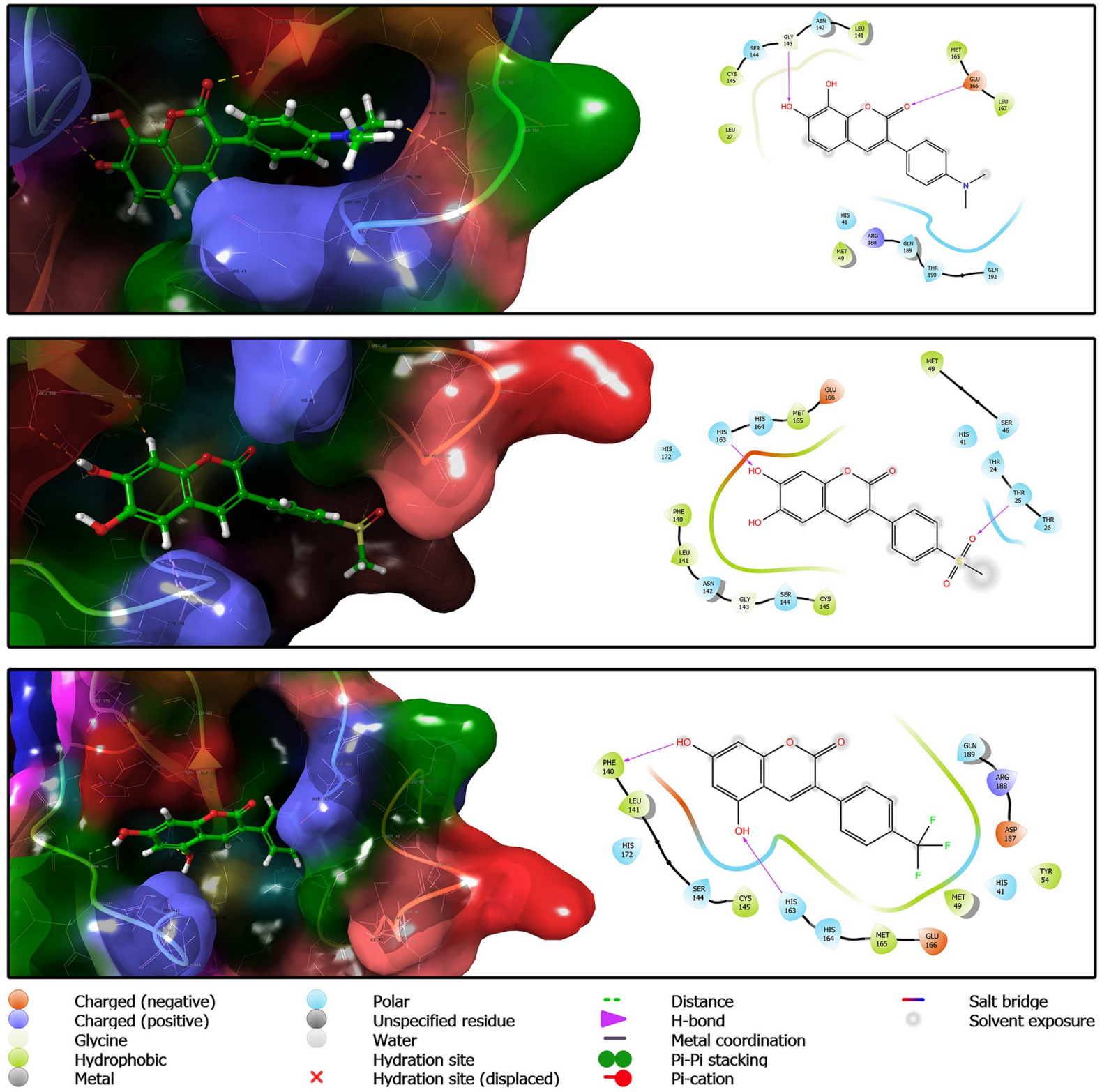

Figure 3. The interaction diagrams of $6 \mathrm{LU} 7$ main protease with docked coumarins in the catalytic domain (left, 3D with residue type surface, and right, 2D). A for compound 1a, B for compound 11b and $C$ for compound 13c. 
A)

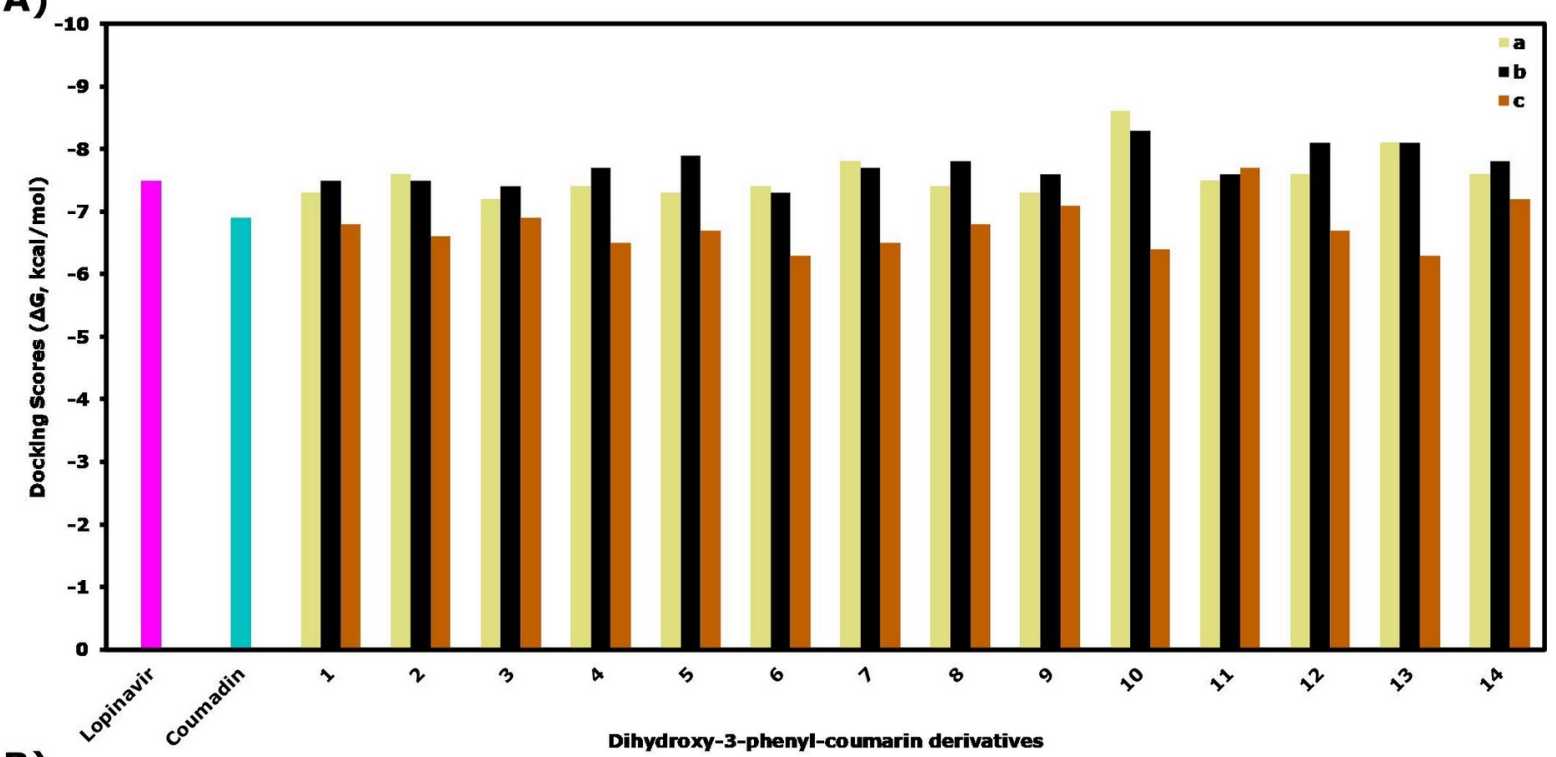

B)

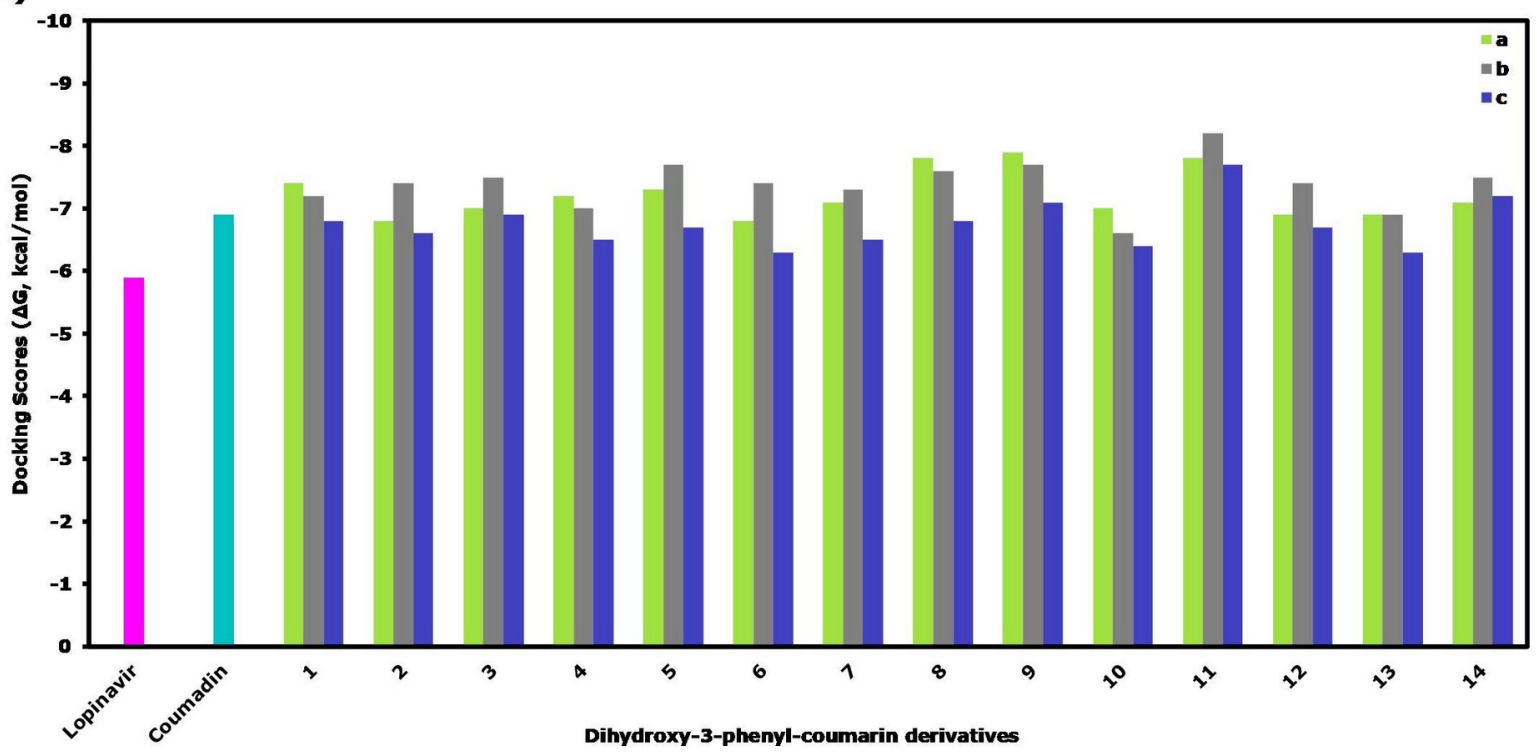

Figure 4. Docking score comparison of all coumarin derivatives (1a-14c) according to reference Coumadin and Lopinavir drug docking scores in Vina (A) and AutoDock (B) Software.

In general, it is observed that the most interaction and hydrogen bond are coumarins containing 4-trifluoromethylphenyl and biphenyl functional groups. The coumarins, which were determined as low scores, scored well compared to the reference drug Coumadin but interacted less with HIS41 and CYS145. Hydrogen bonds are also relatively less than other coumarin derivatives.

\section{Carcinogenicity, Mutagenicity and Pharmacokinetic Properties Prediction} High results have been obtained from the results of tests in gastrointestinal absorption parameters, indicating that all coumarin derivatives are suitable for oral use. The meaning of yes in the cytochrome inhibitor parameter indicates that coumarin compounds have potential as an inhibitor that can lead to the toxic form in the process of cytochrome metabolism. The meaning of no in the cytochrome inhibitor parameter indicates that coumarin compounds have no potential as an inhibitor in the process of cytochrome metabolism.

Bioavailability is one of the basic pharmacokinetic properties of drugs and is used to indicate the rate of drug administration applied to the systemic circulation. The higher 
the bioavailability value of a drug, the more efficiently the drug can be used orally. When the estimation results are examined, all the compounds except 12a-c coumarin are equal to 0.55 . The bioavailability value of the $12 \mathbf{a}-\mathbf{c}$ coumarin compound is 0.56 (Table 4).

Table 4. The ADME parameters of all coumarin (1a-14c) and two references (Coumadin and Lopinavir) compounds via SwissADME software.

\begin{tabular}{lcccccccc}
\hline \multirow{2}{*}{ Ligand } & TPSA & Gl. & \multicolumn{5}{c}{ Cytochrome Inhibitor } & Bioavailability \\
\cline { 4 - 7 } & $\left(\AA^{2}\right)$ & Absorption & CYP1A2 & CYP2C19 & CYP2C9 & CYP2D6 & CYP3A4 & Score \\
\hline $\mathbf{1 a - c}$ & 73.91 & High & Yes & No & No & Yes & Yes & 0.55 \\
2a-c & 79.90 & High & Yes & No & No & Yes & Yes & 0.55 \\
$\mathbf{3 a - c}$ & 95.97 & High & Yes & No & Yes & No & Yes & 0.55 \\
4a-c & 90.90 & High & Yes & No & No & Yes & No & 0.55 \\
$\mathbf{5 a - c}$ & 70.67 & High & Yes & No & No & No & No & 0.55 \\
$\mathbf{6 a - c}$ & 70.67 & High & Yes & No & No & No & No & 0.55 \\
7a-c & 70.67 & High & Yes & No & No & No & No & 0.55 \\
$\mathbf{8 a - c}$ & 70.67 & High & Yes & No & No & No & No & 0.55 \\
$\mathbf{9 a - c}$ & 70.67 & High & Yes & No & No & No & No & 0.55 \\
$\mathbf{1 0 a - c}$ & 70.67 & High & Yes & Yes & No & Yes & No & 0.55 \\
$\mathbf{1 1 a - c}$ & 113.19 & High & No & No & No & No & No & 0.55 \\
$\mathbf{1 2 a - c}$ & 107.97 & High & No & No & No & No & No & 0.56 \\
$\mathbf{1 3 a - c}$ & 70.67 & High & Yes & No & No & No & No & 0.55 \\
$\mathbf{1 4 a - c}$ & 116.49 & High & Yes & No & Yes & No & No & 0.55 \\
Ref1 & 67.51 & High & No & Yes & Yes & No & No & 0.55 \\
Ref2 & 120.00 & High & No & Yes & No & No & Yes & 0.55 \\
\hline
\end{tabular}

ADMET properties of coumarin derivatives $(\mathbf{a}, \mathbf{b}$, and $\mathbf{c}$ ) bearing the same substituent were the same. The change of the position to which the hydroxy functional group is attached did not cause any change in ADMET parameters.

The mutagenicity and carcinogenicity prediction of coumarin derivatives and two reference compounds (Coumadin and Lopinavir) were calculated using Toxtree-v3.1.0.1851 software based on Benigni/Bossa rule base (38) used to estimate carcinogenicity and mutagenicity of ligands according to their skeleton and substituents. The working potential of this process is to identify structure-dependent functional groups known to be associated with the carcinogenic activity of the compounds because if one or more carcinogenic functional groups are identified, the software will mark the carcinogenicity potential of the chemical.

The coumarin skeleton was positive for genotoxic carcinogenicity, but it was reported that warfarin (coumadin) was not carcinogenic and even gave good results in the human body
(39). Of course, unusual effects have also been reported in some cases (40-42). Based on this, carcinogenicity can only be neglected for coumarins, where the coumarin skeleton gives structural alerts. But to say the same thing for coumarins warning other functional groups may pose a risk. For compounds $\mathbf{1 a - c}$, the $p$ dimethylaminophenyl substituent attached to the $\mathrm{C}-3$ position gave warning for genotoxic carcinogenicity. For compounds 14a-c, the pnitrophenyl substituent, linked to the $\mathrm{C}-3$ position, also gave warning of genotoxic carcinogenicity. In the non-genotoxic carcinogenicity analysis, the $\mathrm{p}$-halogenophenyl $(\mathrm{F}, \mathrm{Cl}$, and $\mathrm{Br})$ substituents linked to the $\mathrm{C}-3$ position are positive. Other substituted coumarins are negative except for coumarins that carry these substituents (1a-c and 14a-c). The reference drug component Lopinavir is harmful for both genotoxic carcinogenicity and non-genotoxic carcinogenicity (Table 5). To be able to compare and be sure, all the coumarin derivatives must be validated for toxicity by experimental analysis. 
Table 5. The Carcinogenicity and mutagenicity prediction test of all coumarin derivatives (1a-14c) and two reference compounds (Coumadin and Lopinavir) via Toxtree software.

\begin{tabular}{|c|c|c|c|c|}
\hline Ligand & $\begin{array}{c}\text { Genotoxic } \\
\text { Carcinogenicity }\end{array}$ & $\begin{array}{l}\text { Structural Alert for } \\
\text { Genotoxic } \\
\text { Carcinogenicity } \\
\end{array}$ & $\begin{array}{l}\text { Non-genotoxic } \\
\text { Carcinogenicity }\end{array}$ & $\begin{array}{c}\text { Structural Alert for } \\
\text { Non-genotoxic } \\
\text { Carcinogenicity }\end{array}$ \\
\hline $1 a-c$ & Positive & & Negative & - \\
\hline $2 a-c$ & Positive & & Negative & - \\
\hline $3 a-c$ & Positive & & Negative & - \\
\hline $4 a-c$ & Positive & & Negative & - \\
\hline $5 a-c$ & Positive & & Negative & - \\
\hline $6 a-c$ & Positive & & Negative & - \\
\hline $7 a-c$ & Positive & & Positive & \\
\hline $8 a-c$ & Positive & & Positive & \\
\hline $9 a-c$ & Positive & & Positive & \\
\hline $10 a-c$ & Positive & & Negative & - \\
\hline $11 a-c$ & Positive & & Negative & - \\
\hline $12 a-c$ & Positive & & Negative & - \\
\hline $13 a-c$ & Positive & & Negative & - \\
\hline $14 a-c$ & Positive & & Negative & - \\
\hline Ref1 ${ }^{*}$ & Positive & & Negative & - \\
\hline Ref2 $^{*}$ & Negative & & Negative & - \\
\hline
\end{tabular}

${ }^{*}$ Ref1: Reference drug Coumadin. It has been determined as a reference drug molecule because of its similarity to the subject compounds.

"Ref2: Reference drug Lopinavir. It has been determined as the reference drug molecule because it has an activity for the target protein.

The red-colored structural alert shows that the group has genotoxic carcinogenicity.

The blue-colored structural alert shows that the group has non-genotoxic carcinogenicity. 


\section{CONCLUSION}

In this study, coumarin and its derivatives, which are natural pharmacophore compounds for the development of antiviral agents effective against the SARS-CoV-2 virus, were optimized by density functional theory method to estimate the ideal geometries and properties of molecules and screened using molecular placement studies against 6 LU7 main protease. 42 coumarin derivatives also had better scores than the reference drug coumadin, interacting with residues in the catalytic domain of the main protease. These potential coumarin protease inhibitors have shown an energy score in the range of $-7.1 \mathrm{kcal} / \mathrm{mol}$ to $-8.6 \mathrm{kcal} / \mathrm{mol}$. In general, 6,7-dihydroxy-3-phenylcoumarin derivatives gave relatively higher scores, and for all coumarins, biphenyl (for 10a, $-8.6 \mathrm{kcal} /$ mol; 10b, $-8.3 \mathrm{kcal} / \mathrm{mol}$; 10c $-7.9 \mathrm{kcal} / \mathrm{mol}$ ) and 4-trifluoromethylphenyl (for 13a, -8.1 $\mathrm{kcal} / \mathrm{mol}$; 13b, $-8.1 \mathrm{kcal} / \mathrm{mol} ; 13 \mathrm{c}-8.3$ $\mathrm{kcal} / \mathrm{mol}$ ) substituted coumarin had the highest score. As potential protease inhibitors, in vitro, and in vivo research studies can be conducted to confirm the findings of these coumarin compounds or provide useful ideas and information to scientists working for coumarins.

\section{ACKNOWLEDGEMENTS}

The numerical calculations reported in this paper were fully performed at TUBITAK ULAKBIM, High Performance and Grid Computing Center (TRUBA resources).

Conflict of Interest: Authors have no conflict of interest.

\section{REFERENCES}

1. Lai C-C, Shih T-P, Ko W-C, Tang H-J, Hsueh P-R. Severe acute respiratory syndrome coronavirus 2 (SARS-CoV-2) and corona virus disease-2019 (COVID-19): the epidemic and the challenges. International Journal of Antimicrobial Agents. 2020:105924.

2. Guo $Y-R$, Cao Q-D, Hong Z-S, Tan $Y-Y$, Chen S-D, Jin $\mathrm{H}-\mathrm{J}$, et al. The origin, transmission and clinical therapies on coronavirus disease 2019 (COVID-19) outbreak-an update on the status. Military Medical Research. 2020;7(1):1-10.

3. Lu H, Stratton CW, Tang YW. Outbreak of Pneumonia of Unknown Etiology in Wuhan China: the Mystery and the Miracle. Journal of Medical Virology.
4. Zu ZY, Jiang MD, Xu PP, Chen W, Ni QQ, Lu GM, et al. Coronavirus disease 2019 (COVID-19): a perspective from China. Radiology. 2020:200490.

5. Singhal T. A review of coronavirus disease-2019 (COVID-19). The Indian Journal of Pediatrics. 2020:1-6.

6. Cascella $M$, Rajnik $M$, Cuomo $A$, Dulebohn SC, Di Napoli R. Features, evaluation and treatment coronavirus (COVID-19). Statpearls: StatPearls Publishing; 2020.

7. Rothan HA, Byrareddy SN. The epidemiology and pathogenesis of coronavirus disease (COVID-19) outbreak. Journal of Autoimmunity. 2020:102433.

8. Al-Tawfiq JA. Asymptomatic coronavirus infection: MERS-CoV and SARS-CoV-2 (COVID19). Travel Medicine and Infectious Disease. 2020.

9. Lauer $\mathrm{SA}$, Grantz $\mathrm{KH}, \mathrm{Bi} \mathrm{Q}$, Jones $\mathrm{FK}$, Zheng $Q$, Meredith $H R$, et al. The incubation period of coronavirus disease 2019 (COVID-19) from publicly reported confirmed cases: estimation and application. Annals of Internal Medicine. 2020;172(9):577-82.

10. Hill MA, Mantzoros C, Sowers JR. Commentary: COVID-19 in patients with diabetes. Metabolism. 2020.

11. Fang L, Karakiulakis G, Roth M. Are patients with hypertension and diabetes mellitus at increased risk for COVID-19 infection? The Lancet Respiratory Medicine. $2020 ; 8(4): e 21$.

12. Zheng $Y-Y$, Ma $Y-T$, Zhang J-Y, Xie $X$. COVID-19 and the cardiovascular system. Nature Reviews Cardiology. 2020;17(5):25960.

13. Terpos E, Ntanasis-Stathopoulos I, Elalamy I, Kastritis E, Sergentanis TN, Politou $M$, et al. Hematological findings and complications of COVID-19. American Journal of Hematology. 2020.

14. Ranucci $M$, Ballotta $A$, Di Dedda $U$, Bayshnikova E, Dei Poli M, Resta M, et al. The procoagulant pattern of patients with COVID-19 acute respiratory distress syndrome. Journal of Thrombosis and Haemostasis. 2020.

15. Connors JM, Levy JH. COVID-19 and its implications for thrombosis and anticoagulation. 
Blood, The Journal of the American Society of Hematology. 2020;135(23):2033-40.

16. Hassan MZ, Osman $\mathrm{H}$, Ali MA, Ahsan MJ. Therapeutic potential of coumarins as antiviral agents. European Journal of Medicinal Chemistry. 2016;123:236-55.

17. Curini $M$, Epifano $F$, Maltese $F$, Marcotullio MC, Gonzales SP, Rodriguez JC. Synthesis of collinin, an antiviral coumarin. Australian Journal of Chemistry. 2003;56(1):59-60.

18. Yang G, Chen D. Biflavanones, flavonoids, and coumarins from the roots of Stellera chamaejasme and their antiviral effect on hepatitis B virus. Chemistry \& Biodiversity. 2008;5(7):1419-24.

19. Ojala $T$, Remes $S$, Haansuu P, Vuorela $H$, Hiltunen $R$, Haahtela $K$, et al. Antimicrobial activity of some coumarin containing herbal plants growing in Finland. Journal of Ethnopharmacology. 2000;73(1-2):299-305.

20. Smyth T, Ramachandran V, Smyth W. A study of the antimicrobial activity of selected naturally occurring and synthetic coumarins. International Journal of Antimicrobial Agents. 2009;33(5):421-6.

21. O'reilly RA, Aggeler PM. Studies on coumarin anticoagulant drugs: initiation of warfarin therapy without a loading dose. Circulation. 1968;38(1):169-77.

22. O'Reilly RA, Aggeler PM, Leong LS. Studies on the coumarin anticoagulant drugs: the pharmacodynamics of warfarin in man. The Journal of Clinical Investigation. 1963;42(10):1542-51.

23. O'Reilly RA, Aggeler PM, Hoag MS, Leong L. Studies on the coumarin anticoagulant drugs: the assay of warfarin and its biologic application. Thrombosis and Haemostasis. 1962;8(02):082-95.

24. Gormley NA, Orphanides G, Meyer A, Cullis PM, Maxwell A. The interaction of coumarin antibiotics with fragments of the DNA gyrase B protein. Biochemistry. 1996;35(15):5083-92.

25. Maxwell A. The interaction between coumarin drugs and DNA gyrase. Molecular Microbiology. 1993;9(4):681-6.

26. Frisch MJ, Trucks GW, Schlegel HB, Scuseria GE, Robb MA, Cheeseman JR, et al.
Gaussian 09 Revision C. 01. Wallingford CT: Gaussian, Inc.; 2009.

27. Dennington $R$, Keith $T$, Millam $J$. GaussView, version 6. 2009.

28. Becke AD. Density-functional exchangeenergy approximation with correct asymptotic behavior. Physical Review A. 1988;38(6):3098.

29. Becke AD. Becke's three parameter hybrid method using the LYP correlation functional. The Journal of Chemical Physics. 1993;98:5648-52.

30. Lee C, Yang W, Parr RG. Development of the Colle-Salvetti correlation-energy formula into a functional of the electron density. Physical Review B. 1988;37(2):785.

31. Kohn W, Sham LJ. Self-consistent equations including exchange and correlation effects. Physical Review. 1965;140(4A):A1133.

32. Trott $\mathrm{O}$, Olson AJ. AutoDock Vina: improving the speed and accuracy of docking with a new scoring function, efficient optimization, and multithreading. Journal of Computational Chemistry. 2010;31(2):455-61.

33. Morris GM, Huey $R$, Lindstrom $W$, Sanner MF, Belew RK, Goodsell DS, et al. AutoDock4 and AutoDockTools4: Automated docking with selective receptor flexibility. Journal of Computational Chemistry. 2009;30(16):2785-91.

34. BIOVIA DS. Discovery Studio Visualizer. San Diego, CA, USA. 2017.

35. Schrödinger. Schrödinger Release 20202: Maestro. LLC, New York, NY; 2020.

36. Daina $A$, Michielin $O$, Zoete $V$. SwissADME: a free web tool to evaluate pharmacokinetics, drug-likeness and medicinal chemistry friendliness of small molecules. Scientific reports. 2017;7:42717.

37. Liu $X$, Wang $X-J$. Potential inhibitors against 2019-nCoV coronavirus $M$ protease from clinically approved medicines. Journal of Genetics and Genomics. 2020;47(2):119.

38. Benigni R, Bossa $C$, Tcheremenskaia O. Nongenotoxic carcinogenicity of chemicals: mechanisms of action and early recognition through a new set of structural alerts. Chemical reviews. 2013;113(5):2940-57. 
39. Pollock BE. Clinical experience with warfarin (coumadin) sodium, a new anticoagulant. Journal of the American Medical Association. 1955;159(11):1094-7.

40. Nath SK, Sandhu AP, Rose BS, Simpson DR, Nobiensky PD, Wang J-Z, et al. Toxicity analysis of postoperative image-guided intensity-modulated radiotherapy for prostate cancer. International Journal of Radiation Oncology* Biology* Physics. 2010;78(2):43541.

41. Keskin S, Gökmen İE, Koç O, Özbek O. Unusual complication of coumadin toxicity mimicking Crohn's disease. Case Reports. 2014;2014: bcr2013202755.

42. Baer S, Yarrow MW, Kravitz C, Markson V. Clinical experiences with warfarin (coumadin) sodium as an anticoagulant. Journal of the American Medical Association. $1958 ; 167(6): 704-8$ 


\section{In silico, 6LU7 protein inhibition using dihydroxy-3-phenyl coumarin derivatives for SARS-CoV-2}

Mücahit Özdemir, Baybars Köksoy, Deniz Ceyhan, Mustafa Bulut, Bahattin Yalçın

\section{Supporting Information}

\section{CONTEXT}

Figure S1. Present of 6LU7 Main Protease with wire (left) and residue type surface (right).

Figure S2. The active site of 6LU7 Main Protease.

Figure S3. Optimized geometry, HOMO-LUMO orbitals, electron density surface and energy values of 7,8-dihdyroxycoumarins (1a-14a).

Figure S4. Optimized geometry, HOMO-LUMO orbitals, electron density surface and energy values of 6,7-dihdyroxycoumarins (1)-14b).

Figure S5. Optimized geometry, HOMO-LUMO orbitals, electron density surface and energy values of 5,7-dihdyroxycoumarins (1c-14c). 

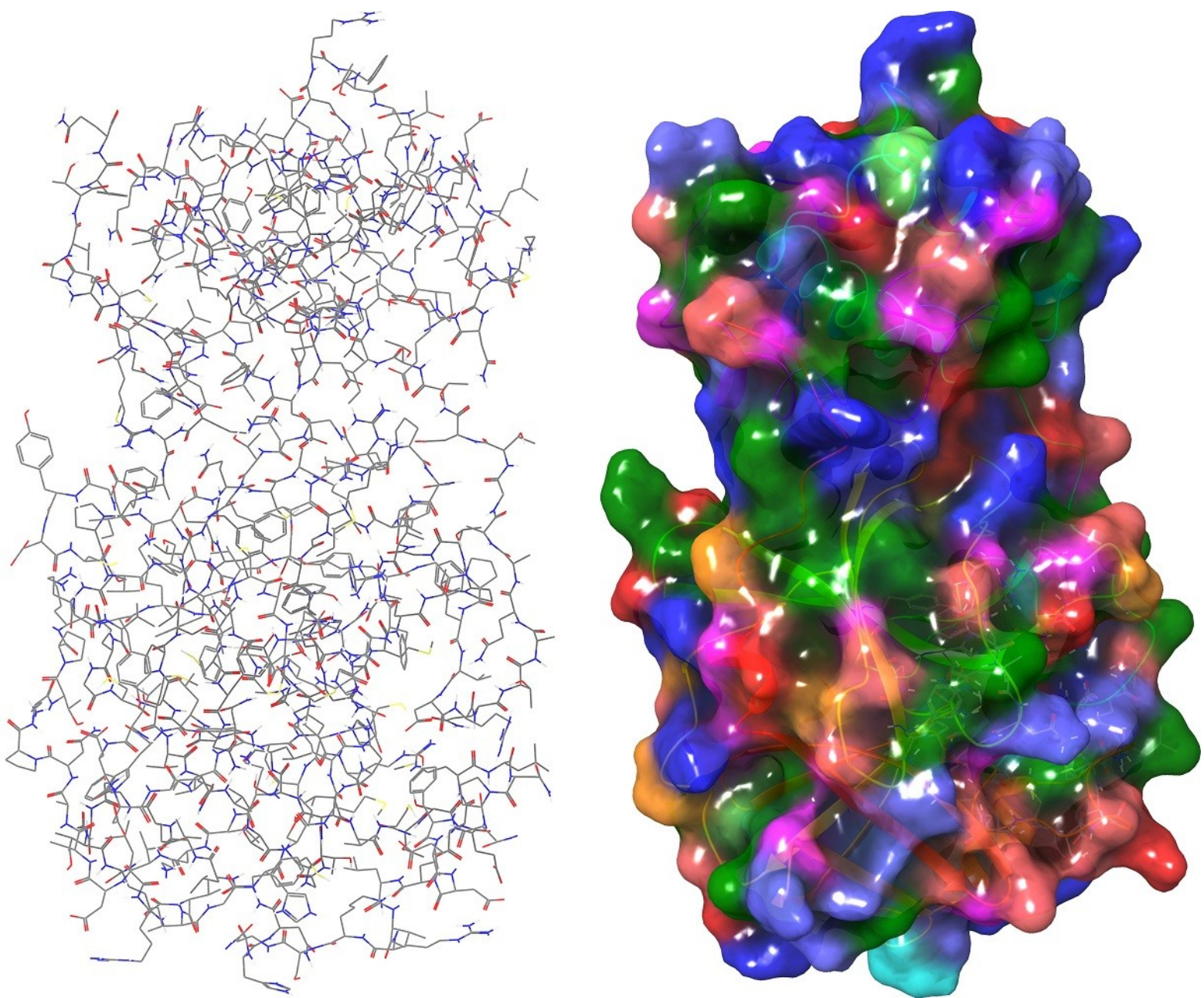

Figure S1. Present of 6LU7 Main Protease with wire (left) and residue type surface (right). 
ÖZDEMİR M et al., 2020; 7(3): 691-712.

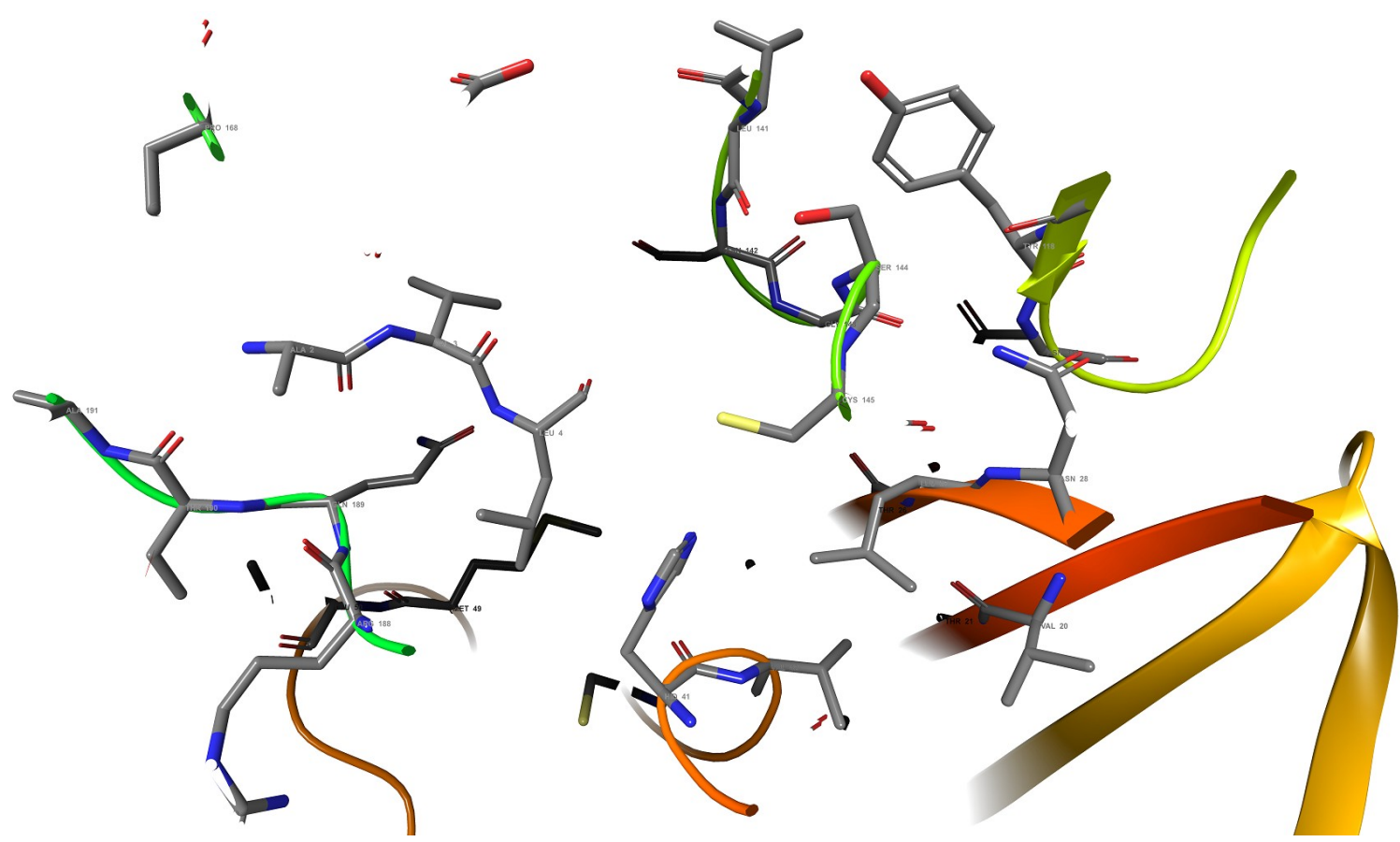

Figure S2. The active site of 6LU7 Main Protease. 
ÖZDEMİR M et al., 2020; 7(3): 691-712.

RESEARCH ARTICLE

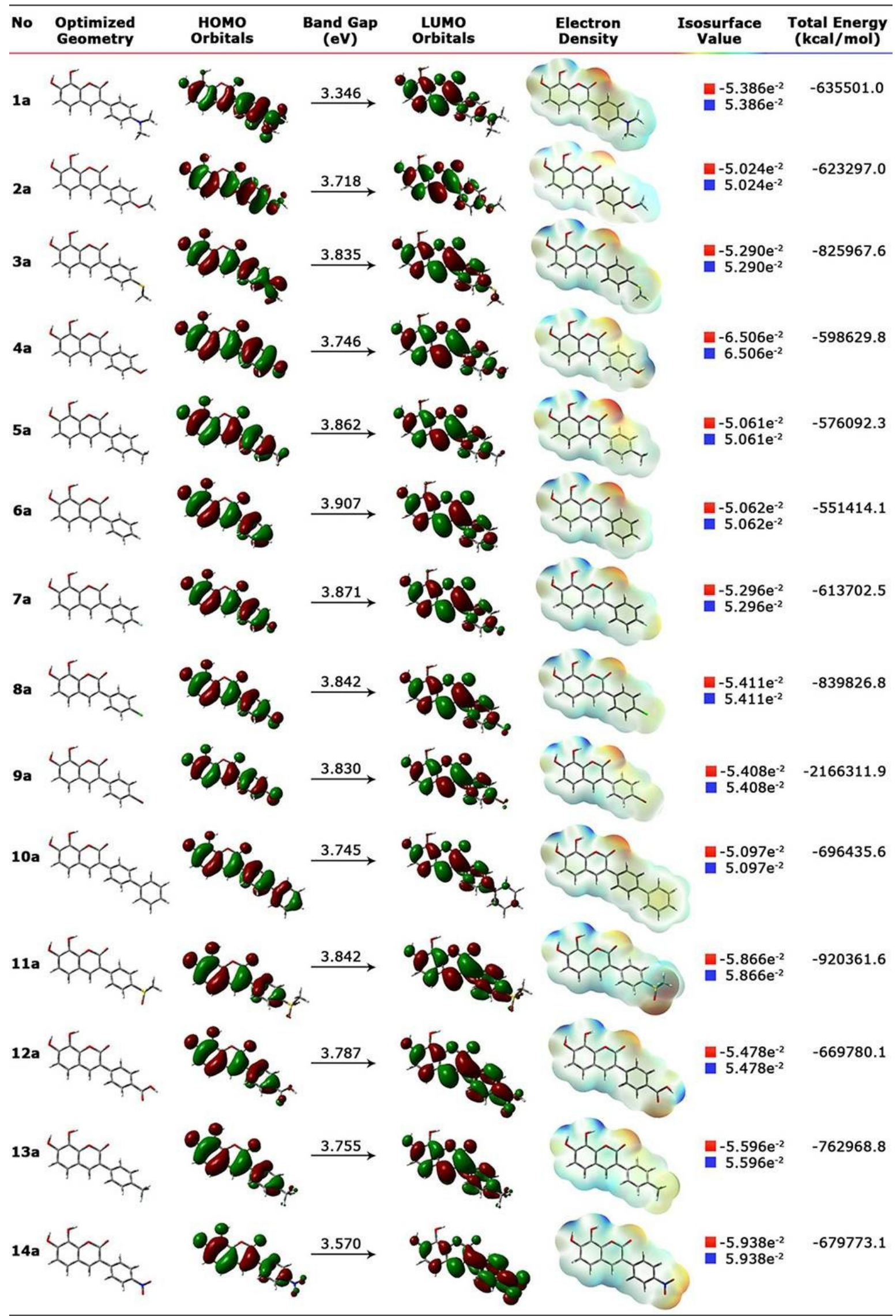

Figure S3. Optimized geometry, HOMO-LUMO orbitals, electron density surface and energy values of 7,8-dihdyroxycoumarins (1a-14a). 


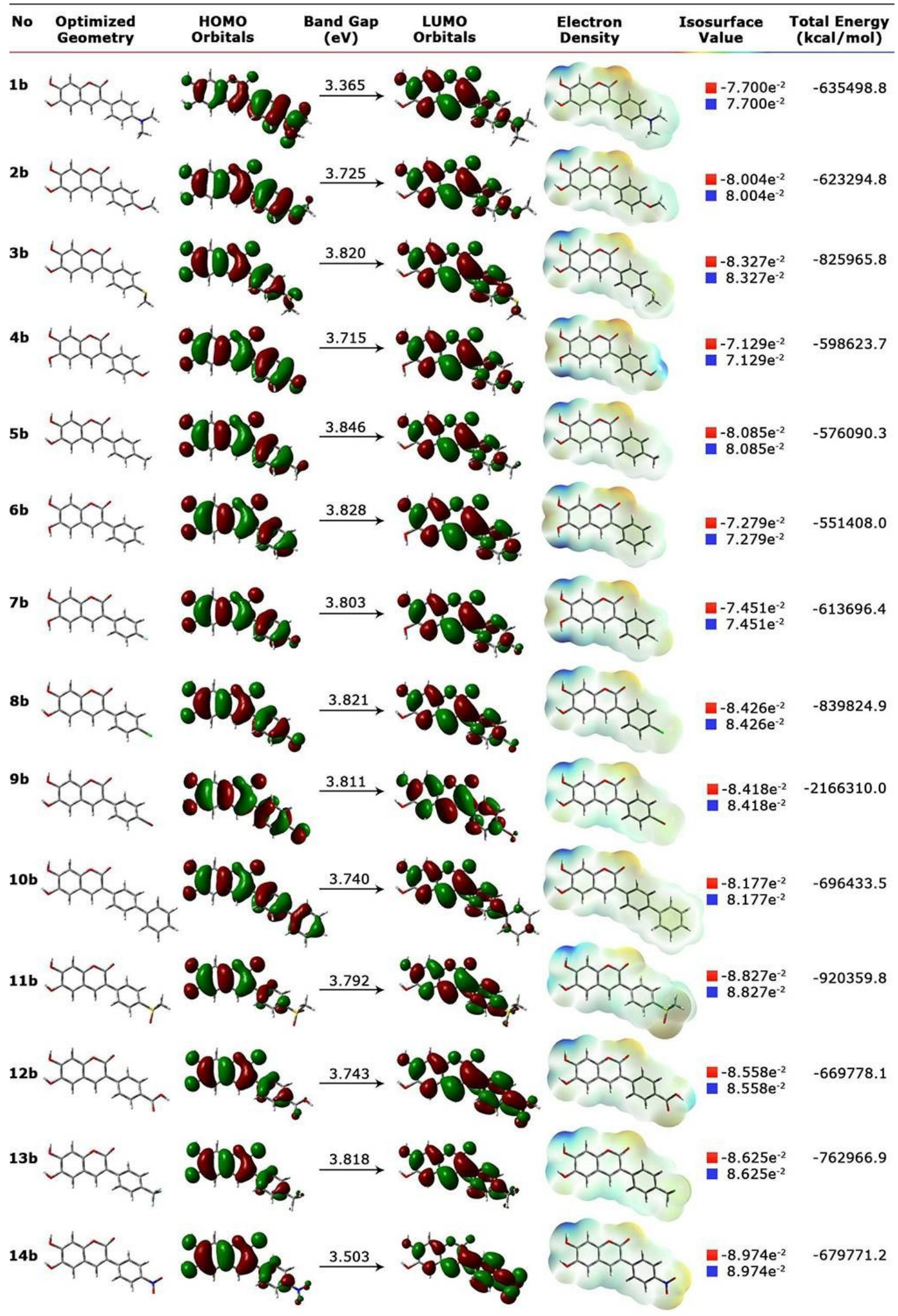

Figure S4. Optimized geometry, HOMO-LUMO orbitals, electron density surface and energy values of 6,7-dihdyroxycoumarins (1b-14b). 


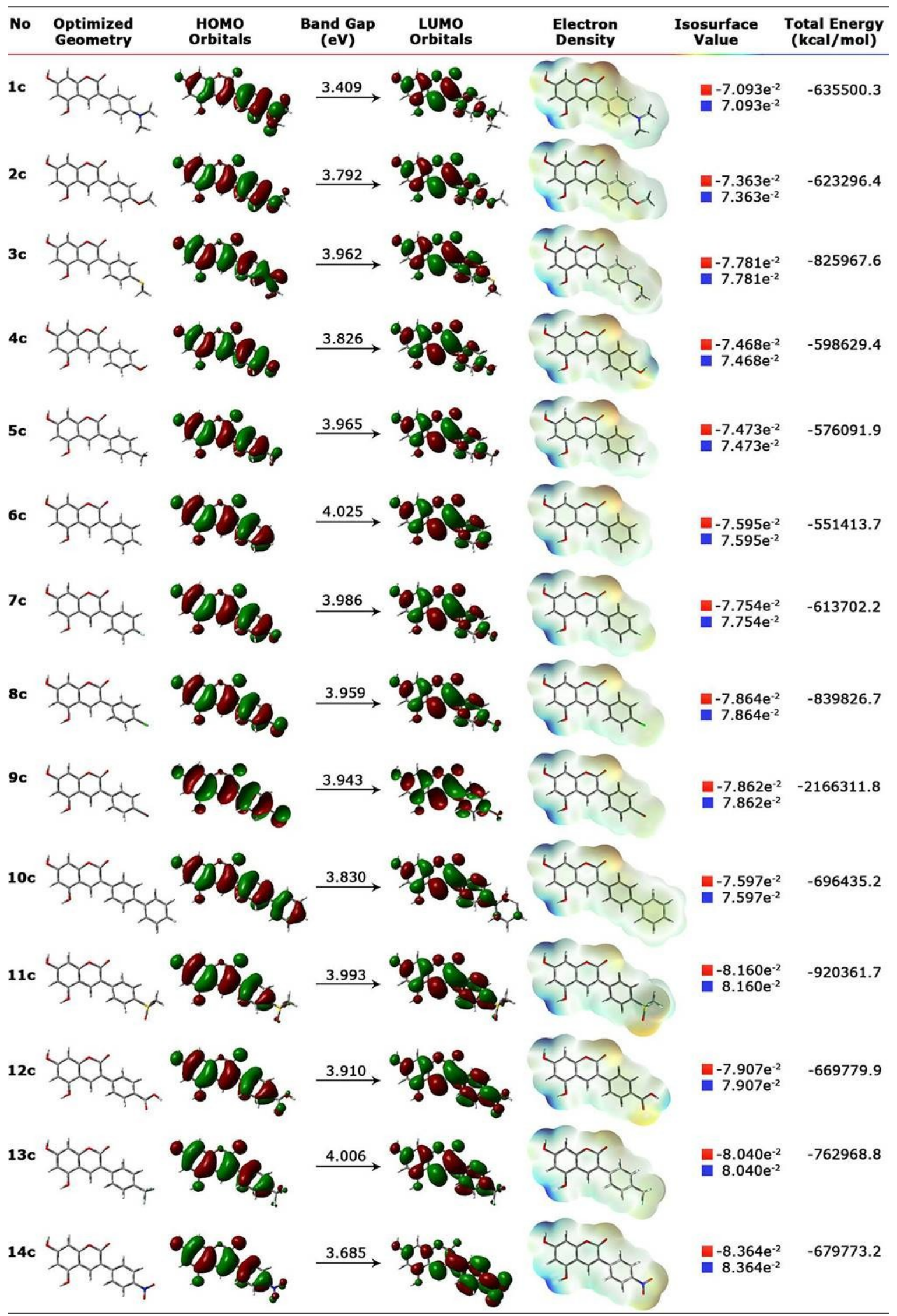

Figure S5. Optimized geometry, HOMO-LUMO orbitals, electron density surface, and energy values of 5,7-dihdyroxycoumarins (1c-14c). 